\title{
Protein Expression Profile of Oral Premalignant Lesions (OPLs)
}

\author{
Kamal Uddin Zaidii ${ }^{1}$, Firoz Naem Khan ${ }^{1}$, Gayatyri Yadav ${ }^{2}$, Vijay Thawani ${ }^{1}$ and Richa Parmar ${ }^{1}$ \\ ${ }^{1}$ Biotechnology Pharmacology Laboratory and Immunology Laboratory, People's University, India \\ ${ }^{2}$ Department of Biochemistry, LN Medical College Bhopal, India
}

Submission: July 24, 2018; Published: August 17, 2018

*Corresponding author: Kamal Uddin Zaidi, Biotechnology Pharmacology Laboratory and Immunology Laboratory, Centre for Scientific Research and Development, People’s University, Bhopal 462037, India, Email: zaidi.kamal92@gmail.com

\begin{abstract}
The progression in cure, early detection and degeneration of oral squamous cell carcinoma (OSCC) remain a key factor to improve the survival rate of patients, in which an elevated proportion of patients are diagnosed at an advanced stage. Current developments in molecular biology research enhanced the understanding of molecular process in OSCC progression and led to identification and characterization of numerous biomarkers. These biomarkers are expected to facilitate the early detection of primary and relapsed tumors. In the present research, we evaluate potential biomarkers for the early detection of OSCC.
\end{abstract}

Keywords: Carcinoma; Biomarkers; Protein; Serum; Cancer; Tumor

\section{Introduction}

Oral cancer is a subgroup of head and neck cancer which affects various regions within oral cavity i.e., lips, tongue, salivary glands, and gums. It is the sixth most common cancer, approximately $3 \%$ of the total cancer burden and results in 128,000 annual deaths globally [1,2]. The most common type of oral cancer is oral squamous cell carcinoma (OSCC), which accounts $90 \%$ of all oral cancer cases. Patients with OSCC are often diagnosed at a late stage, thus high recurrence rate occurs after treatment, especially in those with neck lymph node metastasis [3]. Despite clinical and treatment advances, the overall 5-year survival rates for oral cancer remains low and stagnant during past few decades [4,5]. Although OSCC is commonly diagnosed through oral examination followed by histopathology and computed tomography/positron emission tomography scanning, there has been continuous interest in developing serum protein biomarkers to aid the diagnosis. Tumor antigens are promising diagnostic biomarkers for human cancers showing the clinical utility of tumor antigens, such as carcinoembryonic antigen (CEA), CA-50, CA19-9 and squamous cell carcinoma antigen (SCCA) for OSCC detection [6-9].

Serum SCCA appeared to be more sensitive than the other tumor antigens and positive in $38.1 \%$ and $41.4 \%$ of OSCC patients under testing $[8,10]$. Studies also revealed other potential serum protein biomarkers i.e., CYFRA 21-1 (cytokeratin 19-fragments), tumor polypeptide antigen (TPA) and insulin-like growth factor binding protein $3[9,11]$. CYFRA $21-1$ has been demonstrated as biomarker for other solid tumors, whereas TPA is a serine protease found in rapidly growing tissue due to its role in forming intermediate filaments of the cellular cytoskeleton, making it a promising candidate for cancer detection. Both CYFRA 21-1 and TPA levels were found to be significantly higher in OSCC patients compared to healthy controls and benign tumor patients, and both reduced in 2-3 weeks after surgical resection of their OSCC lesions [11]. Although the testing serum protein biomarkers as a simple diagnostic tool for oral/head and neck cancer has been well demonstrated but still needs to be further validated in large clinical trials. In this study, proteomics analysis of serum for early detection, evaluation, aggressiveness and occurrence of OSCC were summarized. The emphasis was placed on early detection by serum with histological defined oral carcinoma patients. Protein in tissues, saliva and serum may more accurately reflect the progression of OSCC, so novel approach for the depth research strategy and the sample choice for proteomics are of importance in OSCC biomarker discovery.

\section{Material and Methods}

\section{Sample collection}

Information about chewing habits and other characteristics of the study participants was acquired. Those with the habit were questioned for the frequency of the habit in number per day and duration of the habit in years. The type of lesion in the cases was decided on the basis of careful observation of the oral cavity 
and then blood samples were collected from People's College of Dental Science and Research Centre, Bhanpur Bhopal, over a period of one month. $2-3 \mathrm{ml}$ of blood were taken as samples from the patients having oral premalignant lesions (OPL) (leukoplakia and/or erythroplakia) and stored in sterile vials containing $1.5 \mathrm{mg} / \mathrm{ml}$ EDTA and stored at $-20^{\circ} \mathrm{C}$. Individuals who were not addicted to smoking, tobacco or not habitual areca nut consumer and were not having any prior history of cancer and who had never smoked before in his or her lifetime are defined as a never smoker and were considered as control.

\section{Determination of Protein Content}

\section{Lowry method}

The protein content of serum was determined $1 \mathrm{mg} / \mathrm{mL}$ stock solution of Bovine serum albumin (BSA) was prepared. BSA was dissolved in $0.1 \mathrm{~N} \mathrm{NaOH}$ and used as standard [12]. For preparation of standard curve of BSA different concentration that is $100 \mu \mathrm{g} / \mathrm{mL}$ to $1000 \mu \mathrm{g} / \mathrm{mL}$ of BSA was prepared in clean glass tubes and volume was made up to $1 \mathrm{~mL}$ using Millipore water. To each tube, $5 \mathrm{~mL}$ of alkaline solution was added and the tubes were incubated at room temperature for $10 \mathrm{~min}$. After incubation, $0.5 \mathrm{~mL}$ of Folin's reagent was added and was incubated at room temperature in dark for 30 minutes. Violet to blue colour was developed. The intenity of colour was propotional to protein

Table 1: Protein profile of Oral Premalignant lesions. concentration. After incubation the absorbance was measured at $660 \mathrm{~nm}$. Standard curve was prepared by plotting protein (BSA) concentration on X-axis and O.D on Y-axis. A blank was prepared by taking $1 \mathrm{~mL}$ of Millipore water in tube in which $5 \mathrm{~mL}$ of alkaline solution and $0.5 \mathrm{~mL}$ of Folin's reagent were added. All the procedures were carried out in triplets. Estimation of protein contents was done in a same manner as BSA standard curve.

\section{Sodium dodecyl sulphate polyacrylamide gel electrophoresis (sds-page)}

Poly acrylamide gel electrophoresis in the presence of sodium dodecyl sulphate was performed according to LaemmLi [13]. The SDS-PAGE was performed using a $12 \%$ separating gel and $4 \%$ stacking gel. The samples were heated for $5 \mathrm{~min}$ at $100{ }^{\circ} \mathrm{C}$ in capped vials with $1 \%(\mathrm{w} / \mathrm{v}$ ) SDS in the presence of $\beta$-mercaptoethanol. Electrophoresis was performed at a 125 $\mathrm{V}$ for $4 \mathrm{~h}$ in Tris- $\mathrm{HCl}$ buffer of $\mathrm{pH}$ 8.3. After electrophoresis, proteins in the separating gel were made visible by staining with Coomassie Brilliant Blue R-250. The standards were used to make a plot of log molecular weight versus mobility of the protein band were myosin $(200 \mathrm{kDa}), \beta$-galactosidase $(120 \mathrm{kDa})$, bovine serum albumin $(91 \mathrm{kDa})$, glutamate $(62 \mathrm{kDa})$, ovalbumin (43kDa), glyceraldehyde-3-phosphate dehydrogenase (36kDa), carbonic anhydrase $(29 \mathrm{kDa})$, myoglobin $(26 \mathrm{kDa})$, and lysozyme (14kDa) as markers [6] (Table 1).

\begin{tabular}{|c|c|c|c|}
\hline Total no. of Sample & No. of Pattern & No. of Sample & Polymorphic Band(kDa) \\
\hline \multirow{3}{*}{30} & 1 & 8 & $66,75,95,110,140$ \\
\cline { 2 - 4 } & 2 & 5 & $11.5,2390.5$ \\
\cline { 2 - 4 } & 3 & 3 & $18.5,23,66,97$ \\
\cline { 2 - 4 } & 4 & 7 & $14,18,42,130$ \\
\cline { 2 - 4 } & 5 & 3 & $67.5,75,95,110$ \\
\cline { 2 - 4 } & 6 & 4 & $14.5,38.5,55.5$ \\
\hline
\end{tabular}

\section{Results and Discussion}

The OPLs (leukoplakia/erythroplakia) case sample was collected from OPLs patients of PCDS\&RC, People's University, Bhopal the sample size was 20 in which 3 were females and 17 were males under the age group of 18 to 60 . Taking into consideration the addictions, 11 of them were habitual of smoking either bidi or cigarette, 6 were betel nut consumers whereas most of them were pouch/gutkha consumers. Among the sample population, female: male ratio observed was 3:17, where females account for $30 \%$ and males $70 \%$. Total population (OPLs cases) age range varies from 18 to 68 years, of which 1868 and 25-54 was age range of males and females respectively. Among the observed population 38\% were smokers, $21 \%$ were betel nut consumers and majority i.e., $41 \%$ were pouch and gutkha consumers. Biomarkers have been wide accepted in other disciplines but there is no consensus for their use in oral malignancies. Despite recent advances in surgical, radiotherapy, and chemotherapy treatment protocols, the survival of patients with OSCC still lacks significant improvement. This unsatisfactory treatment may be explained by the fact that OSCCs frequently present with extensive local invasion and advanced stages $[14,15]$. That makes necessary the development of new tools for the diagnosis and prognosis.

\section{Protein Profiling}

\section{Total protein}

From the known concentration of protein, the standard curve was plotted, and protein content of the clinical isolates were observed. The total proteins were estimated which revealed the difference in Oral premalignant lesions. The protein concentration ranged from $3.2-11.8 \mathrm{mg} / \mathrm{mL}$. Control group the protein concentration ranged from 2.87-8.35 (Figure 1). Oxidation of protein plays an important role in pathogenesis of cancer and studies have demonstrated decreased protein levels in cases of OPMD's and oral malignancy $[16,17]$. In oral cancer, tobacco and areca nut related habit leading to tissue damage and resultant free radicals play a major role as an aetiologic factor. These habits are seen commonly in all the ages and both the sex. 
The serum protein levels were decreased in OSMF, OL and NS but increased in OM. This difference was statistically significant. These findings are fill agreement of with the findings of Patidar et al. [18] and Rajendran et al. [19] in OSMF participants and Dawood et al. [20] in OM participants. In contrast our results did not simulate with the finding of Chandran et al. [16] in OM group where the plasma protein levels were found to be decreased. The increase in serum protein levels may be explained in terms of inflammatory reaction associated with oral malignancy.

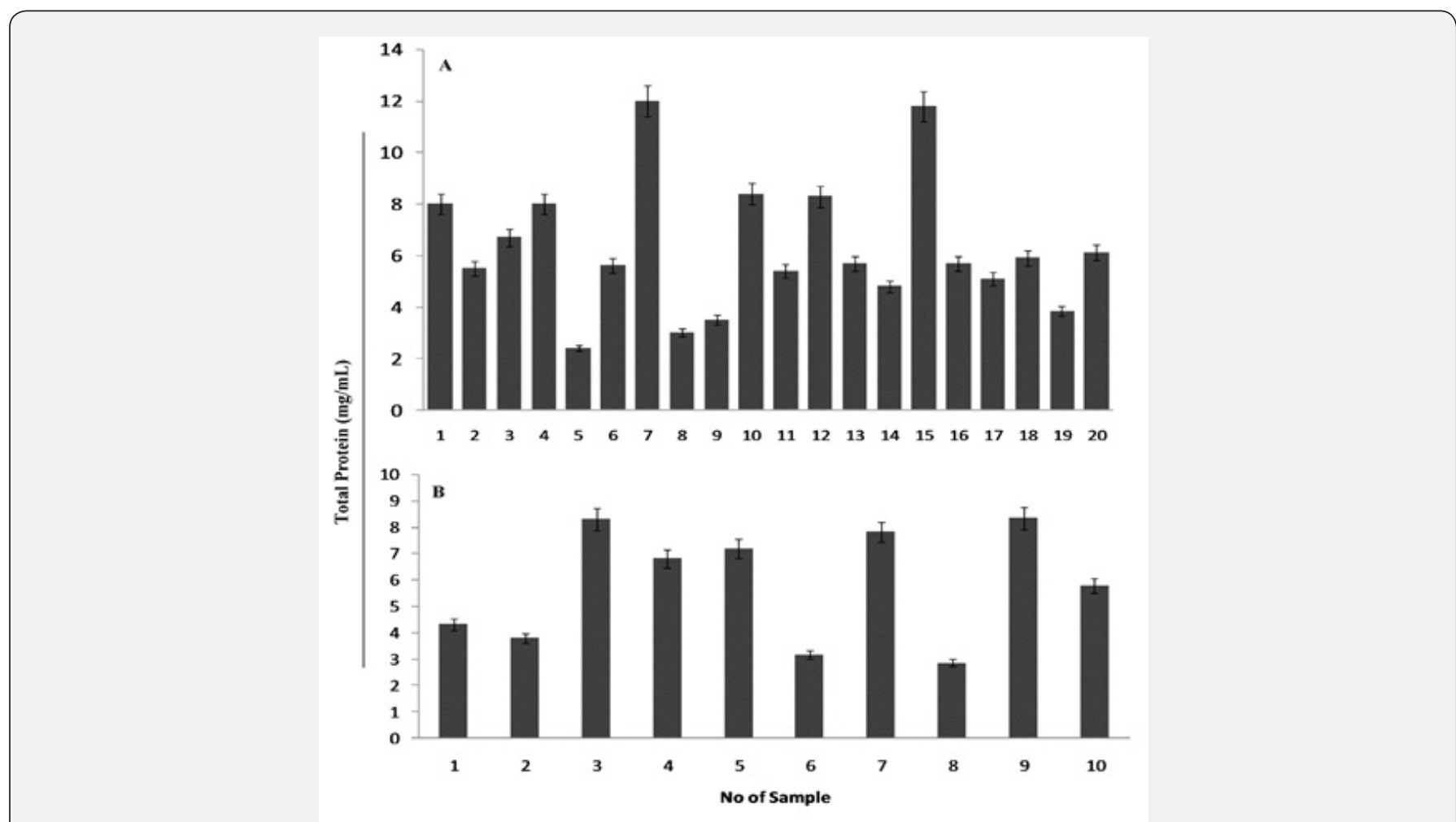

Figure 1: Total Protein: Oral Premalignant lesions $[\mathrm{A}]$ Control $[\mathrm{B}]$.

\section{Sodium dodecyl sulfate polyacrylamide gel electrophoresis}

SDS-PAGE analysis of various samples revealed at least 06 types of banding patterns, with the number of bands ranging from 25 to 40 . The maximum number of sample 26.6\%) had a banding pattern with 04 bands. Proteins with molecular weights $66 \mathrm{kDa}, 75.0 \mathrm{kDa}, 95,110$ and $140 \mathrm{kDa}$ were consistently present in the in the pattern. The pattern 2 showed number of $16.6 \%$ sample had a banding pattern with 03 proteins bands with molecular weights $11.5,23$, and $90.5 \mathrm{kDa}$. The pattern 3 (10\% sample) showed 04 proteins bands with molecular weights 118.5, 23, 66 and 97kDa. Pattern 4 showed number of $23.3 \%$ sample had a banding pattern with 04 proteins bands with molecular weights 14, 18, 42 and130kDa. Pattern 05 also showed number of $10 \%$ sample with 04 proteins bands with molecular weights 67.5,75,95 and110kDa. Pattern 6 revealed 03banding pattern with molecular weights14.5, 38.5, 55.5kDa. Feng et al. [21] measured the level of some biomarkers (SCCA, Cyfra 21-1, epidermal growth factor receptor (EGFR) and Cyclin D1) in an attempt to determine the usefulness of their combined determination in the diagnosis of OSCC. They concluded that Cyclin D1, the product of the CCND1 gene located on chromosome 11q13, had the highest diagnostic specificity. Moreover, the combined detection of EGFR and Cyclin D1 (36kDa) had the highest sensitivity, specificity and accuracy. A previous study Capaccio et al. [22] demonstrates that Cyclin D1expression was significantly associated with the presence of occult lymph node metastases. These data suggest that the immunohistochemical analysis of Cyclin D1 expression in diagnostic biopsy samples may be an additional tool for selecting patients to be treated with elective neck dissection.

The dendrogram showed that the samples [12] were grouped in two closely related clusters. The clusters of Oral Premalignant lesions were significantly different from an unrelated to that of the control. It was also seen that sample from control tended to fall close together on cluster analysis. In our study, the SDSPAGE pattern revealed several characteristic bands common to all samples.

The sample under study was divided in to 2 clusters with cluster 1 having 12 sample and cluster 2 with 18 samples having a similarity $82.5 \%$ and dissimilarity of $17.5 \%$ in the jaccard's coefficient scale ion the dendogram (Figure 2). The cluster 1 was further divided into $1 \mathrm{a}$ and $1 \mathrm{~b}$ with 3(OPLs-18, OPLs-08 OPLs-14,) and 9 (Control-10, Control-07, Control-6, Control-3, OPLs-16, OPLs-13, OPLs-07, OPLs-03, OPLs-05) sample respectively. The cluster 2 was also divided in to two 
sub-cluster 2a (1) (Control-1) and 2b (17) (OPLs-17, OPLs-04, OPLs-12, OPLs-20, OPLs-02, OPLs-10, Control-09, Control-08, Control-04, Control-02, OPLs-06, OPLs-15, Control-5, OPLs-
19, OPLs-11, OPLs-01, OPLs-09). Cluster 2a having 1 sample showed similarity $88.7 \%$ and dissimilarity of $10.5 \%$. $2 \mathrm{~b}$ showed similarity $87.3 \%$ and dissimilarity of $12.3 \%$ (Figure 2).

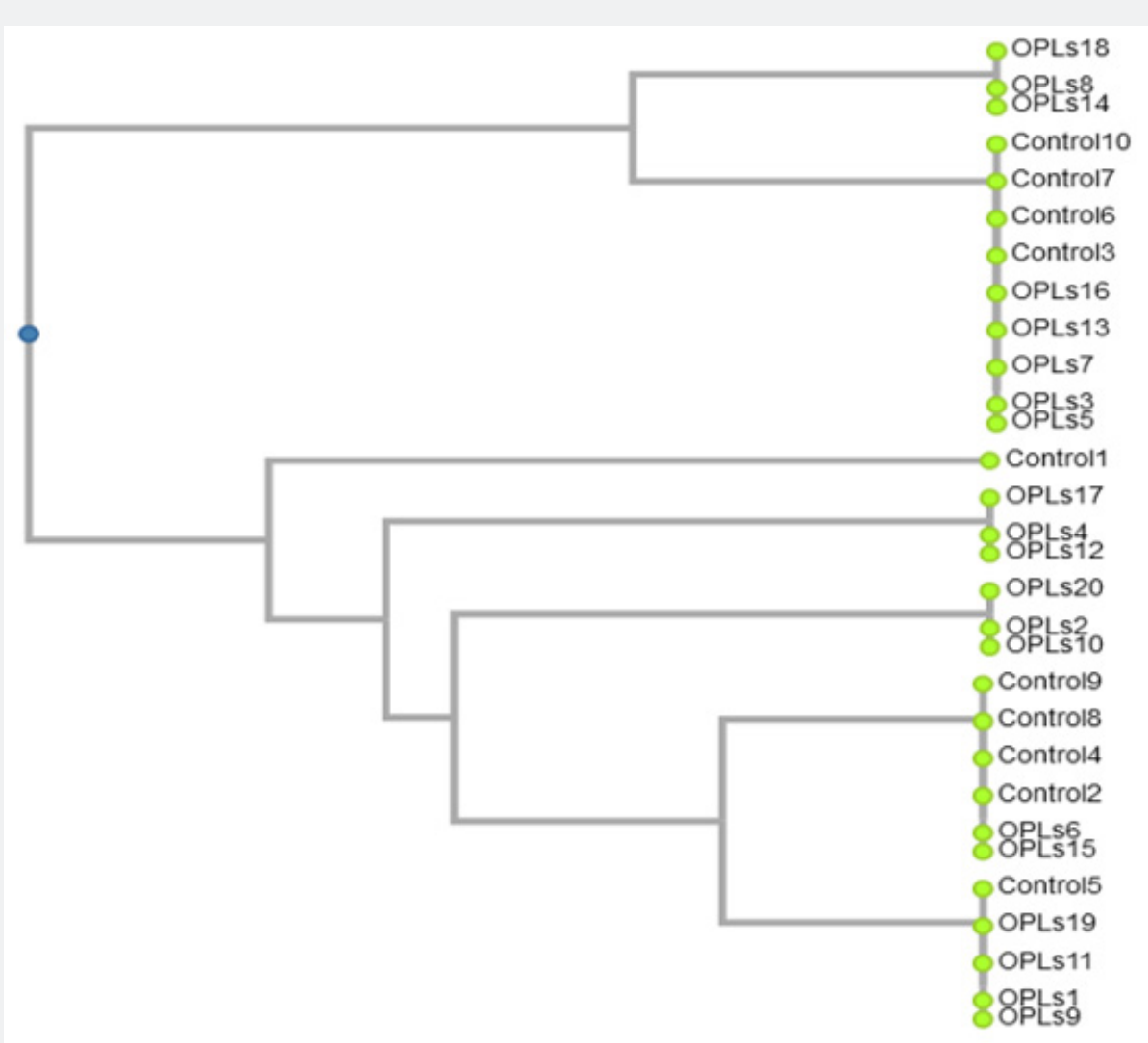

Figure 2: Dendro UPGMA: relationship among Oral premalignant lesions based on their protein profiles by SDS-PAGE.

The sub-cluster 2(b) was also sub divided into sub sub cluster as $2 \mathrm{~b} 1$ (OPLs-17, OPLs-04, OPLs-12) showed similarity $87.9 \%$ and dissimilarity of $12.1 \%$. Cluster as 2 bII (OPLs-20, OPLs-02, OPLs-10, Control-09, Control-08, Control-04, Control-02, OPLs06, OPLs-15, Control-5, OPLs-19, OPLs-11, OPLs-01) showed similarity $86.1 \%$ and dissimilarity of $13.9 \%$. These differences between the samples are due to the difference in their protein profile which can be mediated due to the difference in the oral premalignant lesions therapy. The study clearly indicates that the profile of total protein from Oral Premalignant lesions can be used for developing classification pattern. The cluster $2 \mathrm{bII}$ was also sub divided into sub cluster as $2 \mathrm{~b} 1 \mathrm{Ia}$ and $2 \mathrm{~b} 1 \mathrm{Ib}$ (Control-09, Control-08, Control-04, Control-02, OPLs-06, OPLs15, Control-5, OPLs-19, OPLs-11, OPLs-01) showed similarity $87.9 \%$ and dissimilarity of $12.1 \%$ (Figure 2). Cluster analysis has been used, allowing one to make a more objective interpretation of immunoprofiles, based on staining with multiple antibodies, and holding great promise for the immunohistochemical classification of tumors [23].

Ideally, a good clinical test requires high sensitivity and specificity. The oral cavity is commonly subject to inflammation from a variety of causes, including trauma, dental plaque, infection and certain mucocutaneous inflammatory diseases.
Whether such oral inflammation (non-neoplastic conditions) affects the levels of the potential OSCC serum biomarkers is essentially unknown, because most studies investigated the potential biomarker levels only in OSCC and non-OSCC, without regard to other inflammatory conditions present [24]. If any OSCC biomarkers levels increases in the presence of oral inflammation to the level of OSCC patients, it would result in a high false positive rate and greatly reduce the value of that biomarker in clinical use for detection. Many of reported potential OSCC biomarkers, such as IL-6 [25], IL-8, IL-1 $\beta$ [26], basic fibroblast growth factor [27] and molecules related to oxidative stress [27] are known to be important factors involved in inflammation and/or wound healing [28]. Indeed, the levels of some of these constituents have been reported to be significantly higher or lower in periodontitis or OLP patients who did not have OSCC [29]. Therefore, research that validates any potential OSCC biomarker with individuals having common non-neoplastic oral inflammatory diseases is necessary in order to establish the reliability of that salivary OSCC biomarker

\section{Conclusion}

Serum biomarkers obtained represent a promising approach for oral cancer detection, and an area of strong research interest. 
However, some issues/challenges needs to be determined in order to establish this approach as a reliable, highly sensitive and specific for clinical use, including lack of consistency of serum sample collection, processing and storage; wide variability in the levels of potential oral carcinoma serum biomarkers in both non-cancerous individuals and oral carcinoma patients; and further validation of oral carcinoma serum biomarkers with individuals either a chronic oral inflammatory disease or other types of cancers, but do not have oral carcinoma. Research for eventual standardization especially biological and physiological variance affecting the potential biomarkers gained importance in serum diagnostics. This approach can be useful in monitoring non-cancerous disease activity applying serum biomarkers for other forms of cancer.

\section{Acknowledgement}

The authors are thankful to People's University, Peoples Group, Bhopal, for laboratory facilities, to carry out this research work.

\section{References}

1. Boring CC, Squires TS, Tong T, Montgomery S (1994) Cancer statistics. CA Cancer J Clin 44(1): 7-26.

2. Jemal A, Bray F, Center MM, Ferlay J, Ward E, et al. (2011) Global cancer statistics. CA Cancer J Clin 61(2): 69-90.

3. Day GL, Blot WJ (1992) Second primary tumors in patients with oral cancer. Cancer 70(1): 14-19.

4. Lippman SM, Hong WK (2001) Molecular markers of the risk of oral cancer. N Engl J Med 344(17): 1323-1326.

5. Park BJ, Chiosea SI, Grandis JR (2011) Molecular changes in the multistage pathogenesis of head and neck cancer. Cancer Biomark 9: 325-339.

6. Hoffmann J, Munz A, Krimmel M, Alfter G (1998) Intraoperative and postoperative kinetics of serum tumor markers in patients with oral carcinoma. J Oral Maxillofac Surg 56: 1390-1393.

7. Krimmel M, Hoffmann J, Krimmel C, Cornelius C, Schwenzer N (1998) Relevance of SCC-Ag, CEA, CA 19.9 and CA 125 for diagnosis and followup in oral cancer. J Craniomaxillofac Surg 26: 243-248.

8. Kurokawa H, Yamashita Y, Tokudome S, Kajiyama M (1997) Combination assay for tumor markers in oral squamous cell carcinoma. J Oral Maxillofac Surg 55: 964-966.

9. Brady G, O Regan E, Miller I, Ogungbowale A, Kapas S, et al. (2007) Serum levels of insulin-like growth factors (IGFs) and their binding proteins (IGFBPs), $-1,-2,-3$, in oral cancer. Int J Oral Maxillofac Surg 36: $259-262$.

10. Kurokawa H, Tsuru S, Okada M, Nakamura T, Kajiyama M (1993) Evaluation of tumor markers in patients with squamous cell carcinoma in the oral cavity. Int J Oral Maxillofac Surg 22: 35-38.

11. Nagler R, Barak M, Peled M, Ben-Aryeh H, Filatov M, et al. (1999) Early diagnosis and treatment monitoring roles of tumor markers Cyfra 21-1 and TPS in oral squamous cell carcinoma. Cancer 85(5): 1018-1025.

12. Lowry OH, Rosebrough NJ, Farr AL, Randall RJ (1951) Protein measurement with the Folin phenol reagent. The Journal of Biological Chemistry 193: 265-275.
13. Laemmli UK (1970) Cleavage of structural proteins during the assembly of the head of bacteriophage T4. Nature 227(5259): 680685.

14. Chang KP, Wu CC, Fang KH, Tsai CY, Chang YL, et al. (2013) Serum levels of chemokine (C-X-C motif) ligand 9 (CXCL9) are associated with tumor progression and treatment outcome in patients with oral cavity squamous cell carcinoma. Oral Oncol 49(8): 802-807.

15. Chang KP, Chang YT, Liao CT, Yen TC, Chen IH, et al. (2011) Prognostic cytokine markers in peripheral blood for oral cavity squamous cell carcinoma identified by multiplexed immunobead-based profiling. Clin Chim Acta 412: 980-987.

16. Chandran V, Anitha M, Avinash SS, Rao GM, Shetty BV, et al. (2012) Protein oxidation: A potential cause of hypoalbuminemia in oral cancer. Biomedical research 23(2): 227-230.

17. Nayyar AS, Khan M, Vijayalaxmi KR, Suman B, Gayitri HC (2012) Serum total protein albumin and advanced oxidation protein products Implications in oral squamous cell carcinoma. Malaysian J Pathol 34(1): 47-52.

18. Patidar KA, Parwani RN, Wanjari SP (2011) Correlation of salivary and serum IgG, IgA levels with oral protein in oral submucous fibrosis. J Oral Sci 53(1): 97-102.

19. Rajendran R, Vasudevan DM, Vijavakumar T (1990) Serum levels of iron and proteins in oral submucous fibrosis. Ann of Dent 49(2): 23-25.

20. Dawood RM, Hasan HR (2013) Assessment of salivary and serum proteins in patients with oral tumours. Baghdad Science Journal 10(3): 934-943.

21. Feng XY, Li JH, Li JZ, Han ZX, Xing RD (2010) Serum SCCA, cyfra 211 , EGFR and cyclin D1 levels in patients with oral squamous cell carcinoma. Int J Biol Markers 25(2): 93-98.

22. Capaccio P, Pruneri G, Carboni N, Pagliari AV, Quatela M, et al. (2000) Cyclin D1 expression is predictive of occult metastases in head and neck cancer patients with clinically negative cervical lymph nodes. Head Neck 22(3): 234-240.

23. Begnami MD, Fregnani JH, Brentani H (2012) Identification of protein expression signatures in gastric carcinomas using clustering analysis. J Gastroenterol Hepatol 27: 378-384.

24. Wu J, Yi C, Chung H, Wang D, Chang W, et al. (2010) Potential biomarkers in saliva for oral squamous cell carcinoma. Oral Oncology 46: 226-231.

25. SahebJamee M, Eslami M, Atarbashi Moghadam F, Sarafnejad A (2008) Salivary concentration of TNFalpha, IL1 alpha, IL6, and IL8 in oral squamous cell carcinoma. Med Oral Patol Oral Cir Bucal 13(5): 292295.

26. Arellano-Garcia ME, Hu S, Wang J, Henson B, Zhou H, et al. (2008) Multiplexed immunobead-based assay for detection of oral cancer protein biomarkers in saliva. Oral Dis 14(8): 705-712.

27. Vucicevic BV, Cikes N, Lukac J, Virag M, Cekic-Arambasin A (2005) Salivary and serum interleukin 6 and basic fibroblast growth factor levels in patients with oral squamous cell carcinoma. Minerva Stomatol 54(10): 569-573.

28. Mankan AK, Lawless MW, Gray SG, Kelleher D, McManus R (2009) NFkappaB regulation: the nuclear response. J Cell Mol Med 13 (4): 631643.

29. Rhodus NL, Cheng B, Myers S, Bowles W, Ho V, et al. (2005) A comparison of the pro-inflammatory, NF-kappaB-dependent cytokines: TNF-alpha, IL-1- alpha, IL-6, and IL-8 in different oral fluids from oral lichen planus patients. Clin Immunol 114(3): 278-283. 


\section{Your next submission with Juniper Publishers will reach you the below assets}

- Quality Editorial service

- Swift Peer Review

- Reprints availability

- E-prints Service

- Manuscript Podcast for convenient understanding

- Global attainment for your research

- Manuscript accessibility in different formats

( Pdf, E-pub, Full Text, Audio)

- Unceasing customer service

Track the below URL for one-step submission https://juniperpublishers.com/online-submission.php 